\title{
Some Assembly Required: Scaffolding in the Classroom
}

\author{
Adrian Rodgers \\ Dept. of Teaching and Learning \\ The Ohio State University \\ Ohio, USA \\ rodgers.50@osu.edu
}

\begin{abstract}
Scaffolding involves a more targeted approach to teaching. Teachers tend to have challenges on arrange the instruction so that the needs of differentiated learners are addressed. The challenges of scaffolding learning is compounded by the fact that most curricular materials are designed to support teaching to the middle and do not necessarily help with those students who need extra assistance. Scaffolding is not straightforward. It needs effective work from an analytical stance by the teachers. Teachers account for what the learner has to be able to do, the learner's present abilities, the materials that will lift performance, the amount of help that will be needed, and the kind of help that will be needed so that the child can work as independently and successfully as possible.
\end{abstract}

Keywords—strategies, teaching and learning approach, scaffolding.

\section{DEFINING SCAFFOLDING}

When change the existing teaching practices, the teachers naturally think about what problems they might encounter. In the case of scaffolding, teachers tend to think about problems that might arise as a result of changing the way in which working with students[1]. The root of these challenges may lie with the difficulty in defining what scaffolding is and how it might be used. The scaffolding can be seen as a process that.

- Occurs at the point of difficulty and within the students' zone of proximal development.

- Operates as a back-and-forth interaction between teacher and student, where the teacher supports, the student responds, and the teacher alters the level or kind of support accordingly

- Is informed by careful teacher observation of the student in order to determine the amount of support needed

- Occurs at the instructional level so that the student can move forward to more independent learning

- Includes a range of possible instructional procedures

- Is grounded in theory and in practice

Using scaffolding means that teachers must

- Be deeply committed to knowing each child and how to best work with the child

- Know what needs to be taught, and how what needs to be taught fits in the bigger body of knowledge

- Know the instructional procedures that will assist the student(s) in need
- Be flexible in meaning multiple needs simultaneously

- Have a clear vision of the desired outcome

- Be willing to consider alternatives to the status quo and to undertake some instructional risks in undertaking new practices

These characteristics of scaffolding and of teachers who want to use scaffolding allow teachers to realize goals that are targeted directly at teaching students, rather than just meeting curricular guidelines mandated by a school or a district. Scaffolding instructions allow the teacher to

- Work successfully with the most difficult-to-teach students

- Develop a structured approach to support students as they learn the new or difficult material of procedures

- Customize instruction for individual learners or small group of learners

- Economize instruction by targeting assistance where and when it is needed

Although scaffolding can be used to achieve powerful goals, teachers may find it somewhat challenging to do.

\section{CHALLENGES OF SCAFFOLDING}

Scaffolding involves a more targeted approach to teaching, a stark contrast to the more common form of classroom organization in which the teacher leads activities that are directed at the whole class [1]. With this more common instructional approach, teachers often teach to the middle of the class, an approach that favors students achieving fairly easily and quickly at about an average level. Organizing instruction so that the needs of differentiated learners are addressed (because after all, every learner is different), will be a challenge for anyone who is accustomed to teaching to the middle. On the other hand, anyone who is accustomed to teaching to the middle and not satisfied with teaching only some of their students will likely want to invest the time it takes to differentiate instruction [2].

Compounding the challenge of scaffolding learning is the fact that most curricular materials are designed to support teaching to the middle and do not necessarily help with those students who need extra assistance [2]. This is perhaps not the fault of curriculum developers since it is difficult to anticipate what a teacher might need to assist the struggling student.

In some cases, it is difficult to know how to help students who are having difficulty learning to read. The teachers often know what does not work since they may have pulled a number of previously useful tools from our tools from our 
toolbox of instructional strategies and used them without success [2]. Conformed within this failure, teachers continue to look for what does work. At first, the teachers might think that an extra pair of hands might assist us, and they might call in the help of a parent volunteer or perhaps a paraprofessional working in our room. Certainly, these individuals might be of assistance, especially after finding out what works, but in the early stages of trying to identify how teacher might scaffold student learning at the point of difficulty, if the teacher does not know how to assist the student, the parent of paraprofessional will not know.

Although the teachers have a moral and ethical responsibility to teach all of the students, including those finding it difficult to learn, teachers are daily faced with the realization that there are not just one struggling students in the room, and they need to meet the needs of each one of them [3]. At the same time, teachers also have an obligation to meet the needs of the whole class, a class with many students who may not need a more scaffold approach. Instruction to meet so many needs will be challenging.

Another challenge with scaffolding instruction is that struggling students who might benefit from a more scaffold instructional approach often have multiple needs. A teacher can scaffold instruction be recognizing the point at which difficulty occurs and then structuring supports at that point to supports learning [4]. When students have multiple difficulties, it is hard for the teacher to know what is difficult for the students or what the child is "not getting," because the multiple problems have disguised the point of difficulty.

Teacher who do a good job of scaffolding student learning are able to tailor their teaching within the zone of proximal development [4]. By this mean, the teacher can follow the Goldilocks principle, offering prompts and directions to the student that are neither too hard nor too easy, but rather are "just right." While this is easy to say, it is difficult to do. Even Goldilocks made mistakes on her way to finding the chair, the bed, and the porridge that can be just right. Clearly, having a sense of what a student is presently able to do so that teacher can tailor the response, involves a set of much more complex decisions. Suffice it to say, it is all too easy for a teacher to inadvertently make things too easy or too hard, and it is all too difficult to find the prompts that are just right.

Even if a teacher is successful in finding prompts that are "just right" in scaffolding student instruction, the nature of teacher-student exchange is different from more typical classroom encounter. Whereas in more typical classroom encounter the teacher might give directions and await a response, in scaffolding student learning the exchange may be more rapid fire and the teacher enters into a back-andforth learning relationship with the students-a relationship where what the teacher does depends on what the student does. Since some teachers are accustomed to talking while students listen, shifting to listening more and observing closely represents a fundamental shift in teaching.

\section{KEY FEATURES OF EFFECTIVE SCAFFOLDING}

Having identified why scaffolding may be challenging to undertake, it could be turn to identify key features of effective scaffolding. Wood and Wood noted that Vygotsky's definition of zone of proximal development leaves us with the task of identifying "the nature of the guidance and the collaboration that promotes development" [5]. So what is the nature of the guidance and collaboration that promotes development?

\section{A. A Knowledge Teacher}

The teachers who have specialized knowledge about teaching early literacy share an understanding of what readers need to be able to do. They teach students what they can try at difficulty such as rereading, looking at parts of words, using knowledge about letter-sound relationships, or incorporating meaning into attempts. But more significantly, although they agree on what to teach, effective teachers who scaffold learning know that they must tailor the timing of their instruction-when they give help-in response to each students' changing abilities in these areas.

These teachers do not operate from a script that directs them to teach a particular scope or sequence of skills on particular days, it comes out of their heads because they know about teaching. This leads naturally to the conclusion that the best person-the most-well-equipped person to scaffold literacy learning, particularly with students having difficulty learning to read-is a trained teacher, not a paraprofessional or parent volunteer.

\section{B. Provide Opportunities for Errors}

Errors are necessary for learning. As Elbers says, they are "occasions for various suggestions, demonstrations or explanations" [6]. They provide opportunities for the student to explore new frontiers in learning, opportunities that are verbally mediated by a tutor [7].

A key feature of the effective scaffolding of literacy performance, therefore, seems to be the provisions for errors to occur. Texts that are neither too easy nor too difficult provide opportunities to explore new frontiers in problemsolving abilities. The Goldilocks principle again!

Too many errors, however, would likely be counterproductive to the learning process, losing the students engagement and contribution to the problem solving. Obviously, without the students' contributions, there can be no interaction.

As David Wood points out though, the instruction cannot be just right 100 percent of the time [8]. From time to time, help will be offered at too high a level without enough support or too low a level with too much support. Consider for example, this interaction between Ken and his teacher Sarah when they were reading together and Ken ran into difficulties with the word lived:

Ken: In a teeny tiny dollhouse-a (omitted the word

lived)

Sarah: You can't skip words

Ken: What is it?

Sarah: What would make sense?

Ken: Mouse (there's a picture of a mouse on the page)

Sarah: Try the first letter

Ken: Wind up.

Sarah: What letter does it start with?

Ken: L

Sarah: What sound does it make?

Ken: Luh

Sarah: So go back and try it again, and think what would make sense and start that way. 
Ken: Wind up.

Sarah: How does it start?

Ken: Luh.

Sarah: What would make sense and start with luh?

Ken: I'm getting there! (said quietly, almost to self)

Sarah: Could it be live or sat? (Requiring Ken to use some visual information)

Ken: Lived!

Even though Sarah gave successively more help when Ken was unsuccessful, she seemed to start out with giving too little help right at the outset. Ken gamely contributes, but it is easy to imagine the interaction breaking down with another student.

What seems to count, therefore, ineffective scaffolding is not necessarily being accurate with the amount of help that the teacher give, every single time the teacher give help, but observing the impact of the amount of help on the student's success. A scaffolding maxim offered by David Wood which fits very well here is to give more help when the student flounders and less help when the student is successful [8].

\section{Decide What to Teach}

Effective scaffolding also involves making decisions about what to teach. Particularly those just emerging into reading or those having difficulty learning to read, make a variety of types of errors during that reading, some representing, for example, an emerging use of visual information and others representing what seems to be just a slip control. For example, a student who has brought one-toone matching under control some weeks previous may still insert or omit a word now and then while reading, even though that student may be able to use visual information in more sophisticated ways, substituting said for shouted and got for going. With a student who usually makes these kinds of substitution but also fails to make a one-to-one match on one line of text while reading, which error should receive attention: when the one to one matching was off and the student failed to notice, or the error of got for going? Which teaching decision will lift the student's current ability, and which one will focus the student on a process that represents old learning?

Certainly not the error in which the one-to-one matching was off. Even though it is the more alarming error because it is such a basic skill for reading, it is not at the student cutting edge of learning; one-to-one matching has already been brought under control. In fact, if the teacher take a student back to that error to fix it, the student will likely be able to fix it quickly and easily, without recalling that the error was even made in the first place. The other errors, though, of using just the initial letter at difficulty are errors at this particular student's cutting edge, and attending to them will lift the student's processing.

The scaffolding process involves first making decisions about whether any attention should be paid to an error. It should not be unusual for a teacher to ignore certain errors because they are not on the student's cutting edge of learning, either because the student will find it too easy or too hard to fix. Wood and Wood describe this features of scaffolding as "domain contingency" in that the teacher has to make decisions about what to teach [5].

\section{Modulating the Level of Help}

To amount of help the teachers give in difficulty should also vary from student to student. Wood and Wood refer to this element of tutoring as "instructional contingency" - or making decisions about how specific the help should be [5]. More or less support can be provided along a continuum that includes telling, demonstrating, directing, or questioning. On this continuum, questioning a student about what to do next will provide the least amount of help ("What you can try?"), whereas telling ("That word is hat") or demonstrating (showing the student what to do) offers more support.

Wood and Wood describe the process of scaffolding as being particularly taxing on "human powers of observation, attention, and memory" [3]. Their observation seems well justified in the context just described. Before stepping on to the scaffold, or lift learning, a teacher needs to weigh up several decisions, such as "What is this student currently able to do?", "What should I teach now?", "Should I let that error go?", "How much help should I give?", "How much help did I just give?", "How successful was the student when I just helped?", or "Should I give more help?" All of those factors seem embedded in the moment-by-moment teaching decisions made by the teachers who are scaffolding learning.

\section{RECONCEPTUALIZING SCAFFOLDING AS A CONTINUUM}

The way in which teachers might use scaffolded approaches is not an either-or proportions. Instead, the teacher can think of scaffolding as a continuum, on which the teacher might move back and forth during the course of the day. Thus, one example of this continuum depicted in Fig.1 is the context of support.

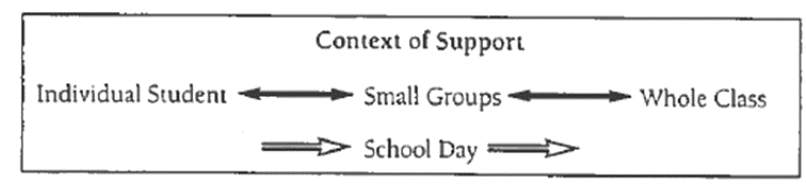

Fig. 1. Context of Support

\section{A. Instructional Choice}

Teachers might also work on a different level, not only concerned about in what grouping they will implement the support structure, but also wondering what the principal task will be. For example, a teacher might choose to deal with an issue regarding the content of a lesson (the word frog begins with letter $f$ ), a concept (frog is a word used to describe a kind of animal), or skill (can you spell frog?). This continuum of instructional choice is depicted in Fig. 2.

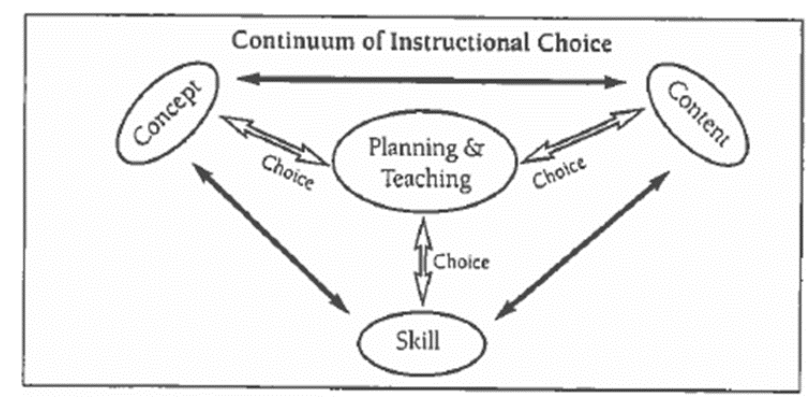

Fig. 2. Continuum of Instructional Choice 


\section{B. Instructional Support}

In addition to the instructional choices the teacher will need to make, the teacher must also make a decision related to how to interact with the child. Will the lesson be governed more by teacher questioning and demonstrating, student responding, or some interrelationship between the two? As further evidence of a continuum, it is likely that during a lesson, this balance will shift depending on how the student responds to the teacher prompts, and therefore at any one time, the teacher will be at a different place on this continuum of interaction. This is depicted in Fig. 3.

Interaction Continuum of Instructional Support

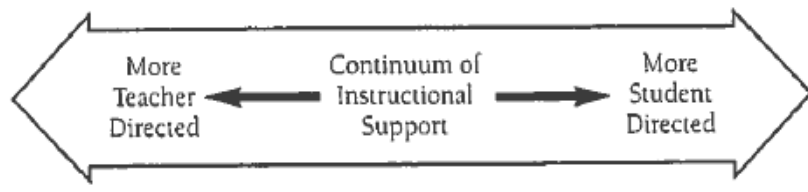

Fig. 3. Interaction Continuum of Instructional Support

\section{Student Need}

An additional concern for teachers is the kind of student issue with which they are dealing. In some cases, a teacher might be dealing with a student or group of students who typically respond well to the less structured form of teaching, and the teacher might only need to use a more scaffolded approach on rare occasions. Thus, this intermittent form of scaffolding might be thought of as incidental, occasional, or centered only around one particular learning problem. On the other hand, in a different year the same teacher may have some students who persistently struggle and who benefit from carefully scaffolded lessons. This range of student needs is depicted in Fig. 4.

\section{Continuum of Student Needs}
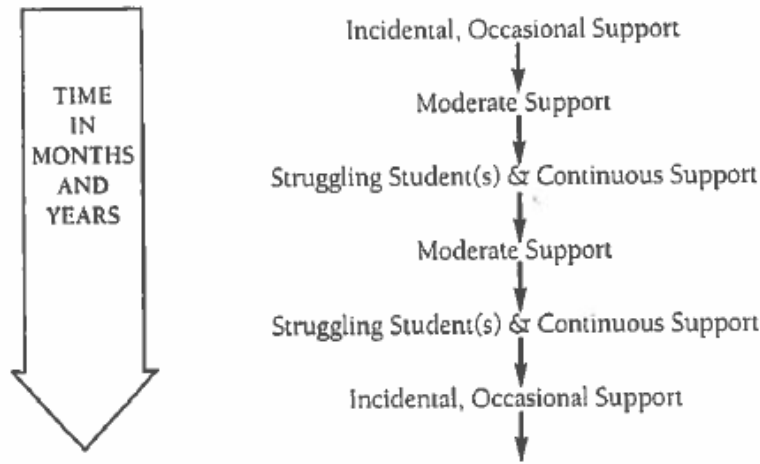

Fig. 4. Continuum of Student Needs

\section{USEFULNESS AND CHALLENGES POSED By SUPPORTS ON MULTIPLE LEVELS}

While it is helpful to think about how scaffolding occurs on a continuum that occupies multiple levels, it is also helpful to think about the usefulness of this continuum and the challenges posed by it. It is depicted in Table 1 .

TABLE I. USEFULNESS AND CHALLENGES POSED By SUPPORT ON MULTIPLE LEVELS

\begin{tabular}{|c|c|c|}
\hline \multicolumn{3}{|c|}{ Usefulness and Challenges Posed by Supports on Multiple Levels } \\
\hline $\begin{array}{c}\text { Continuum of } \\
\text { support }\end{array}$ & Usefulness & Challenges \\
\hline Context of support & - $\quad$ Tailor instruction & Requires \\
\hline
\end{tabular}

\begin{tabular}{|c|c|c|}
\hline \multicolumn{3}{|c|}{ Usefulness and Challenges Posed by Supports on Multiple Levels } \\
\hline $\begin{array}{c}\text { Continuum of } \\
\text { support }\end{array}$ & Usefulness & Challenges \\
\hline Whole Class & $\begin{array}{l}\text { to the needs of } \\
\text { the class, group, } \\
\text { or individual } \\
\text { Differentiation } \\
\text { instruction for } \\
\text { different classes } \\
\text { taught by the } \\
\text { same teacher } \\
\text { Right students } \\
\text { can get support } \\
\text { at the right time, } \\
\text { where and when } \\
\text { they need it }\end{array}$ & $\begin{array}{l}\text { teacher to } \\
\text { weigh needs of } \\
\text { one against } \\
\text { needs of the } \\
\text { many } \\
\text { Requires } \\
\text { teacher to } \\
\text { weigh the } \\
\text { needs of one } \\
\text { student in need } \\
\text { versus another } \\
\text { student who } \\
\text { may be in need } \\
\text { simultaneously } \\
\text { Necessitates } \\
\text { multitasking }\end{array}$ \\
\hline Instructional Choice & $\begin{array}{l}\text { - } \begin{array}{l}\text { Supports teacher } \\
\text { in instructional } \\
\text { choice }\end{array} \\
\text { Represents an } \\
\text { alternative for } \\
\text { teachers who feel } \\
\text { they only teach } \\
\text { "content" } \\
\text { Supports } \\
\text { authentic } \\
\text { teaching and } \\
\text { learning }\end{array}$ & 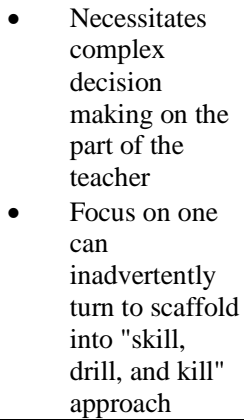 \\
\hline $\begin{array}{c}\text { Instructional } \\
\text { Support } \\
\text { Teacher } \\
\text { Student }\end{array}$ & $\begin{array}{l}\text { - Establishes a } \\
\text { "to" and "for" } \\
\text { approach where } \\
\text { the teacher and } \\
\text { student } \\
\text { interaction } \\
\text { changes } \\
\text { depending on the } \\
\text { student response } \\
\text { to instruction. }\end{array}$ & 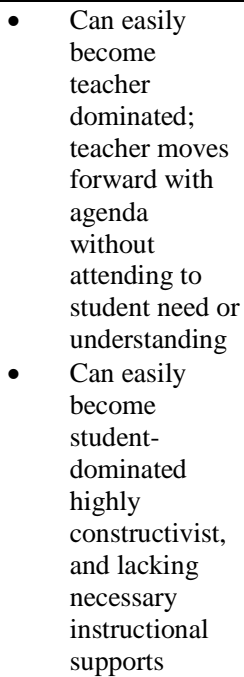 \\
\hline $\begin{array}{l}\text { Student Need } \\
\text { Incidental }\end{array}$ & $\begin{array}{l}\text { Supports right } \\
\text { students getting } \\
\text { the right } \\
\text { instruction at the } \\
\text { right time } \\
\text { Supports teacher } \\
\text { in thinking about } \\
\text { a range of } \\
\text { supports }\end{array}$ & $\begin{array}{l}\text { Difficult to } \\
\text { distinguish } \\
\text { where to apply } \\
\text { scaffolded } \\
\text { support } \\
\text { Easy to think } \\
\text { of an either-or } \\
\text { situation as if } \\
\text { there were } \\
\text { only two } \\
\text { choices rather } \\
\text { than a } \\
\text { continuum of } \\
\text { supports }\end{array}$ \\
\hline
\end{tabular}

What is significant about Table 1 is that it depicts the range of levels on which scaffolding may take place, and the exciting opportunities as well as the risks posed by such carefully targeted instruction. This duality of possibility challenge means that it is essential for teachers to use the range of supports, as described in the preceding figures, to be 
better equipped to provide carefully tailored instruction to students. Although scaffolding offers a range of opportunities for how a teacher might engage a child or a group of children, it is fraught with many challenges which we must consider.

\section{SLIPPERY SLOPES}

Thinking about how teachers might use a more scaffolded approach to lessons offers a great opportunity to teachers, but there are also some slippery slopes that teachers have to negotiate. By slippery slopes, factors beyond the teachers' control that have the effect of pulling them back to the status quo. There are a number of those factors, but the list could be limited to

- $\quad$ standardized testing,

- $\quad$ school and teaching culture, and

- inertia.

\section{A. Standardized Testing}

The first slippery slope is standardized testing. There is no reason that standardized testing should itself represent a barrier to scaffolding student instruction, but it may be that in a particular district, school, or grade level, so much emphasis is placed on these high-stakes, one-shot tests that teachers feel the need to teach to the test to the exclusion of everything else. Indeed, it might even be said that these might have been issues formerly thought to be more relevant to secondary or middle school classrooms, but they now are increasingly faced by teachers of youngest students. This is a difficult slope to climb, and the best advice is that the scaffolded instruction as a way of augmenting or supporting quality learning, which will in turn create a positive performance on things like a standardized test [9]. Another way to think about scaffolding is as a support for some challenged students, and by supporting the learning of students who are "on the bubble," teachers may have impressive outcomes on things such as the pass rate on the standardized test.

\section{B. Culture}

A second slippery slope is the culture of the school and grade level, with particular attention to fellow teachers and their teaching practices. By this, even the teacher might be the most innovative teacher in the world, but if the principal pushes a "team" approach and the teacher in the position of the junior teacher on the Grade 2 team, it may be difficult to move initiatives forward. On the school where a group of thirty-year veteran teachers have referred to one of their colleagues as the "junior teacher" even when that person was a twenty-year veteran! Scaffolding student lessons does offer hope since it should not interfere with the circular planning of the team, but clearly, there are some teams that demand so much of teachers, it is difficult to do anything but follow the vision of the team, which may not necessarily be aligned with the vision of the individual teacher [9]. The best advice in this situations is that an individual teacher might try to articulate how more carefully scaffolded lessons might actually carry the agenda of the team forward, rather than seeing scaffolding as something outside or apart from the efforts of the team.

\section{Inertia}

A third slippery slope is the force of inertia: the difficulty of moving ourselves forward when we are pulled back with our own desire to leave things the way they already are. This is a more complicated way of saying "Don't fix it if it isn't broken." Certainly, there is a lot to be said for leaving things that currently work the way they are. That said, scaffolding student learning might better be thought of as augmenting quality teaching rather than as a wholesale change in teaching [1]. In other words, if lived in a nice house where everything works well except for the television, which does not receive Channel 6, no one is asking to buy a new house with a television that works- merely that change the channel on the television to one that works. Thus, to overcome inertia it can be helpful to think about how scaffolding student learning builds on current teaching repertoire rather than seeing it as an extra task to be accomplished in an already busy day.

\section{USING SCAFFOLDS TO CONSTRUCT TEACHING}

Although teachers have many different ways of defining scaffoldings, it can be said that all scaffolding is teaching, but that not all teaching is scaffolding. Scaffolding is a process of interaction designed to lift learning [4]. Teachers' choices of approaches, curricula, or materials can all work toward this end, especially when materials and resources are used to support new understandings.

Scaffolding is not straightforward. Teachers who are effective seem to work from an analytical stance [4]. They account for what the learner has to be able to do, the learner's present abilities, the materials that will lift performance, the amount of help that will be needed, and the kind of help that will be needed so that the child can work as independently and successfully as possible.

Most importantly, in this era of emphasis on what teachers know and can do, conversations regarding scaffolding place students back at the heart of instructional decision making. Since consideration of the student response is a key element of scaffolded instruction, students have a key role to play in scaffolding. By considering how better scaffold the instruction, teachers should place students back at the center of planning and teaching.

\section{REFERENCES}

[1] B. J. Reiser, "Scaffolding complex learning: The mechanisms of structuring and problematizing student work," J. Learn. Sci., vol. 13, no. 3, pp. 273-304, 2004.

[2] S. D. Brookfield, The skillful teacher: On technique, trust, and responsiveness in the classroom. John Wiley \& Sons, 2015.

[3] S. Park and J. S. Oliver, "Revisiting the conceptualisation of pedagogical content knowledge (PCK): PCK as a conceptual tool to understand teachers as professionals," Res. Sci. Educ., vol. 38, no. 3, pp. 261-284, 2008.

[4] J. Radford, P. Bosanquet, R. Webster, and P. Blatchford, "Scaffolding learning for independence: Clarifying teacher and teaching assistant roles for children with special educational needs," Learn. Instr., vol. 36, pp. 1-10, 2015.

[5] D. Wood and H. Wood, "Vygotsky, tutoring and learning," Oxf. Rev. Educ., vol. 22, no. 1, pp. 5-16, 1996.

[6] E. Elbers, "Cooperation and social context in adult-child interaction," Learn. Instr., vol. 6, no. 4, pp. 281-286, Dec. 1996.

[7] M. Hoogsteder, R. Maier, and E. Elbers, "The architecture of adultchild interaction. Joint problem solving and the structure of cooperation," Learn. Instr., vol. 6, no. 4, pp. 345-358, 1996. 
[8] D. Wood, "The Why? What? When? and How? of Tutoring: The Development of Helping and Tutoring Skills in Children.," Lit. Teach. Learn., vol. 7, pp. 1-30, 2003.

[9] J. van de Pol, M. Volman, F. Oort, and J. Beishuizen, "The effects of scaffolding in the classroom: support contingency and student independent working time in relation to student achievement, task effort and appreciation of support," Instr. Sci., vol. 43, no. 5, pp. 615-641, 2015. 